\title{
INTEGRAÇÃO DAS TDICs NA EDUCAÇÃO: ESPAÇOS DIGITAIS
}

\author{
Jaqueline Corrêa Godinho Souza ${ }^{1}$
}

\section{RESUMO}

Este artigo possui como problema fomentador a ausência de interesse dos professores em aplicar as Tecnologias Digitais da Informação e Comunicação - TDICs - em sala de aula e, também, a sua influência no trabalho desenvolvido em ambientes de ensino. Posto isso, a meta principal deste estudo consiste em descrever o processo de integração das Tecnologias Digitais da Informação e Comunicação - TDICs - em contextos escolares sistemáticos com ênfase nos espaços digitais. Ainda, de modo secundário, busca-se, especificamente, definir a integração das TDICs na educação; identificar a importância da mobilidade digital; e, por fim, detalhar os espaços digitais nas escolas. Tais metas serão consubstanciadas a partir das reflexões teóricas de Tarja (2008); Moran (2004); Lemos e Costa (2007); Pereira (2011) e Leite (2008). A metodologia empregada segue as definições de Severino (2007) no que tange aos estudos bibliográficos modernos, pautando-se em obras de referência, artigos e outras produções acadêmicas. Esse cabedal de informações aqui organizado sob o formato de um artigo justificase por conta da massiva inserção dos indivíduos como um todo no mundo digital, cabendo às escolas uma constante inovação e inserção desses recursos tecnológicos nas salas de aula.

Palavras-chave: Tecnologias Digitais da Informação e Comunicação; Espaços Digitais; Prática Docente.

\begin{abstract}
This article has as a problem the lack of interest of teachers in applying Digital Information and Communication Technologies - TDICs - in the classroom and also their influence on the work developed in teaching environments. Having said that, the main goal of this study is to describe the integration process of Digital Information and Communication Technologies - TDICs - in systematic school contexts with emphasis on digital spaces. Also, in a secondary way, it is specifically sought to define the integration of TDICs in education; identify the importance of digital mobility; and finally detail digital spaces in schools. These goals will be embodied from the theoretical reflections of Tarja (2008); Moran (2004); Lemos and Costa (2007); Pereira (2011) and Leite (2008). The methodology used follows the definitions of Severino (2007) regarding modern bibliographic studies, based on reference works, articles and other academic productions. This information organized here in the form of an article is justified by the massive insertion of individuals as a whole in the digital world, and schools are responsible for constant innovation and insertion of these technological resources in the classrooms.
\end{abstract}

Keywords: Digital Information and Communication Technologies; Digital Spaces; Teaching Practice.

\footnotetext{
${ }^{1}$ Graduação em Língua Portuguesa e Língua Inglesa (Faculdade da Região dos Lagos, 2002). Especialista em Informática Educativa (Faculdade da Região dos Lagos, 2003). Especialista em Supervisão, Inspeção e Orientação pela Universidade Cândido Mendes (2013). Mestra em Ciências da Educação pela Universidad Interamericana no Paraguai (2020). Atualmente professora da Sala de Recursos Multifuncionais da Escola Municipal Professor Zélio Jotha da Secretaria Municipal de Educação de Cabo Frio. E-mail: jaquecgsouza@gmail.com.
} 


\section{RESUMEM}

Este artículo tiene como problema la falta de interés de los profesores en la aplicación de las Tecnologías Digitales de la Información y la Comunicación - TDICs - en el aula y también su influencia en el trabajo desarrollado en entornos docentes. Dicho esto, el objetivo principal de este estudio es describir el proceso de integración de las Tecnologías Digitales de la Información y la Comunicación (TDICs) en contextos escolares sistemáticos con énfasis en los espacios digitales. Además, de manera secundaria, se pretende específicamente definir la integración de las TDICs en la educación; identificar la importancia de la movilidad digital; y finalmente detallar espacios digitales en las escuelas. Estos objetivos se plasmarán en las reflexiones teóricas de Tarja (2008); Moran (2004); Lemos y Costa (2007); Pereira (2011) y Leite (2008). La metodología utilizada sigue las definiciones de Severino (2007) relativas a los estudios bibliográficos modernos, basados en obras de referencia, artículos y otras producciones académicas. Este todo informativo organizado aquí en forma de artículo se justifica por la inserción masiva de personas en su conjunto en el mundo digital, y las escuelas son responsables de la innovación constante y la inserción de estos recursos tecnológicos en las aulas.

Palabras clave: Tecnologías Digitales de la Información y la Comunicación; Espacios Digitales; Práctica Docente.

\section{INTRODUÇÃO}

Cada vez mais, constata-se que a tecnologia tem proporcionado novas formas de relação para a humanidade, ao longo do percurso histórico social, na tentativa de solução de problemas e maior agilidade no desenvolvimento de tarefas. Ao mesmo tempo, percebe-se a importância que esta mesma tecnologia precisa ter no ambiente escolar, entendendo que a escola pode e deve inserir as diferentes mídias para contextualização, aplicação, construção e produção de conhecimento.

O aparato tecnológico, aqui entendido como toda e qualquer produção, criação ou publicação de mídia, já tem feito parte de toda a sociedade e, em contrapartida, permanece, por vezes, distante do processo educativo e, também, da formação inicial e final dos professores.

Desta forma, as Tecnologias Digitais da Informação e Comunicação² (TDICs) na educação visam:

\footnotetext{
${ }^{2} \mathrm{~A}$ TDIC abrange todo o meio técnico usado para tratar a informação e auxiliar na comunicação, fazendo uso de hardwares como computadores, rede, smartphone e, também, dos softwares, denominados aplicativos que elaboram, interferem e medeiam as relações humanas.
} 
[...] fortalecer a produção de culturas e de conhecimentos dentro de uma comunidade e, ao mesmo tempo, olhar pra dentro, para ela própria e para fora, para o mundo. Nesse diálogo construímos mais conhecimentos, mais ciência, mais tecnologia, mais cultura (PRETTO, 2012, p. 99).

É importante ressaltar que, desde o ano de 2007, a educação pública brasileira tem se esforçado nas esferas municipais, estaduais e federais, em regime de participação colaborativa, por meio do Programa Nacional de Tecnologia Educacional ${ }^{3}$ (PROINFO), realizado no âmbito do PDE - Plano Nacional de Desenvolvimento da Educação, para oferecer condições ou um ponto de partida para a promoção da tecnologia em escolas urbanas e rurais.

O desenvolvimento da TDICs na educação passou a ganhar espaço na escola e, paulatinamente, tornou-se recurso imprescindível para a contextualização do conteúdo curricular, produção com o conhecimento e publicação e divulgação, revelando, assim, que, como menciona Kenski (2001):

É necessário que os professores se sintam confortáveis para utilizar esses novos auxiliares didáticos. Estar confortável significa conhecê-los, dominar os principais procedimentos técnicos para sua utilização, avaliálos criticamente e criar novas possibilidades pedagógicas, partindo da integração desses meios com o processo de ensino (KENSKI, 2001, p. 77).

Ainda, citando o texto da LDB, no artigo 211, quando trata da Educação, fica clara a responsabilidade de cada segmento administrativo, como as esferas da União, dos Estados, do Distrito Federal e dos municípios. Nesse mesmo artigo, no $2^{\circ}$ parágrafo, há a afirmação de que "os Municípios atuarão prioritariamente no ensino fundamental e na educação infantil." (BRASIL, 1996, art. $\left.211,2^{\circ} \S\right)$.

Nesse contexto, sobre o acesso à educação, a Constituição de 1988, em seu artigo 214 que trata da Educação, da Cultura e do Desporto, define diretrizes para a elaboração de estratégias que assegurem a melhoria do ensino e a promoção tecnológica do país:

\footnotetext{
${ }^{3}$ O Programa Nacional de Tecnologia Educacional (Prolnfo) é um programa educacional que teve como objetivo promover o uso pedagógico de tecnologia na rede pública de educação básica e foi criado pela Portaria no 522 do Ministério da Educação e Cultura (MEC) em 9 de abril de 1997.
} 


\begin{abstract}
Art. 214. A lei estabelecerá o plano nacional de educação, de duração decenal, com o objetivo de articular o sistema nacional de educação em regime de colaboração e definir diretrizes, objetivos, metas e estratégias de implementação para assegurar a manutenção e desenvolvimento do ensino em seus diversos níveis, etapas e modalidades por meio de ações integradas dos poderes públicos das diferentes esferas federativas que conduzam a: I - erradicação do analfabetismo; II - universalização do atendimento escolar; IIImelhoria da qualidade do ensino; IV-formação para o trabalho; V promoção humanística, científica e tecnológica do País; (grifo nosso) VI - estabelecimento de meta de aplicação de recursos públicos em educação como proporção do produto interno bruto (BRASIL, 1988, art. 214).
\end{abstract}

Dessa forma, tendo em vista a relevância temática aqui descortinada, busca-se, com este estudo, descrever o processo de integração das Tecnologias Digitais da Informação e Comunicação - TDICs - em contextos escolares sistemáticos com ênfase nos espaços digitais.

Ainda, pretende-se alcançar, de modo mais específico, os seguintes objetivos: definir a integração das TDICs na educação; identificar a importância da mobilidade digital; e detalhar os espaços digitais nas escolas. Para tal, este artigo divide-se nas seções Integração das TDICs na Educação; que conta com as subseções Recursos Materiais e Recursos Humanos; seguida de Mobilidade Digital ou Tecnologias Móveis; e, por último, Espaços Digitais - Salas de Informática.

\title{
INTEGRAÇÃO DAS TDICs NA EDUCAÇÃO
}

A reflexão sobre o uso das TDICs na ministração dos conteúdos em sala de aula sempre foi um norteador sobre como e quando essa proposta pode acontecer, pensando na relação metodologia e tecnologia, visto que, neste caso, a metodologia faz toda a diferença em uma proposta de aula. Tarja (2008) discute sobre essa situação, como pode ser observado no trecho a seguir:

A utilização do computador integrada a software educativo não garante uma adequada utilização dessa tecnologia como ferramenta pedagógica. $\mathrm{O}$ fato de um professor estar utilizando o computador para ministrar uma aula não significa, necessariamente, que esteja aplicando uma proposta inovadora. Muitas vezes essa aula é tão tradicional quanto uma aula expositiva com a utilização do giz (TARJA, 2008, p. 49). 
As Diretrizes Curriculares Nacionais também versam sobre esse assunto de modo mais generalista, porém ainda se coadunando às ideias defendidas por Tarja (2008). Mencionam-se a questão do tradicionalismo e da aprendizagem em si. Atrela-se a efemeridade temporal às necessidades educacionais modernas como pode ser observado na passagem a seguir.

[...] enquanto a escola se prende às características de metodologias tradicionais, com relação ao ensino e à aprendizagem como ações concebidas separadamente, as características de seus estudantes requerem outros processos e procedimentos, em que aprender, ensinar, pesquisar, investigar, avaliar ocorrem de modo indissociável. Os estudantes, entre outras características, aprendem a receber informação com rapidez, gostam do processo paralelo, de realizar várias tarefas ao mesmo tempo, preferem fazer seus gráficos antes de ler o texto, enquanto os docentes creem que acompanham a era digital apenas porque digitam e imprimem textos, têm e-mail, não percebendo que os estudantes nasceram na era digital (BRASIL, DCN, 2013, p. 25).

Essa interatividade é fundamental para ensinar novos aspectos e estimular o que eles aprendem. Em idades mais novas, a interatividade pode ser um fator determinante no interesse do aluno pelo que se aprende. Esse aspecto se mantém ao longo da vida escolar. É preciso estar sempre atualizado para poder manter a atenção dos alunos, principalmente em eras tão digitais. Conciliar tais demandas da escola moderna aos desafios diários enfrentados pelas unidades escolares parece ser algo impossível já previsto por Morán (2004) ao afirmar que as TDICs

[...] estão trazendo novos desafios pedagógicos para as universidades e escolas. Os professores, em qualquer curso presencial, precisam aprender a gerenciar vários espaços e a integrá-los de forma aberta, equilibrada e inovadora. O primeiro espaço é o de uma nova sala de aula equipada e com atividades diferentes, que se integra com a ida ao laboratório conectado em rede para desenvolver atividades de pesquisa e de domínio técnico-pedagógico (MORAN, 2004, p. 8).

Com tantos problemas que circundam a educação no Brasil, infraestrutura, segurança, falta de pessoal capacitado, não seria de se estranhar que integrar as TDICs de modo efetivo e realmente eficaz nas unidades escolares seria um grande desafio. Além das dificuldades elencadas, pode-se somar a isso a resistência do corpo de professores para o novo. 
O que se deve ter em mente é que não há como retroagir, as mudanças chegaram e vão e devem alterar a rotina escolar, a fim de fazer valer o que dizem das diretrizes, portarias, normas e leis que norteiam a prática educativa em território brasileiro e garantir um ensino que comtemple todas as frentes modernas relacionadas à educação.

\section{RECURSOS MATERIAIS}

A questão da infraestrutura é um ponto relevante e que deve ter uma atenção especial dos governantes, diretores escolares e da sociedade como um todo. Os recursos materiais são essenciais para colocar em prática a integração das TDICs na sala de aula. Sem estrutura, computadores, acesso à rede e aos tablets fica difícil colocar em prática o que se apregoam os aparatos legais vigentes.

A dificuldade de conexão nas escolas é uma questão que só pode ser superada com investimento em conexões de mais qualidade. Com poucos recursos, o uso de tecnologias mobile não é tão eficiente. Reverter esse cenário, exige a mobilização das esferas pública e privada para firmar parcerias que ofertem o essencial.

Na base desse processo, está a autonomia econômica mínima para acesso aos bens e aos serviços tecnológicos. O capital cultural é a memória de uma sociedade, o social, a potência política e identitária, o intelectual a competência individual, e o técnico a potência da ação e da comunicação (LEMOS; COSTA, 2007, p. 112).

Paralelamente, a cidade moderna e informacional do século XXI tem como princípio fundamental a cultura da mobilidade de informações, objetos, tecnologias e pessoas. As mídias expandem a compreensão de mundo e dos próprios indivíduos, produzindo subjetividade. Elas ampliaram o genérico "outro" e a relação que estabelecemos com o lugar, dada a visão expandida de outros lugares (pela experiência ou pelas mídias). Desde sempre, mídias produzem espacialização e subjetividade, historicizando-se pela escrita; vindo depois os jornais, o rádio, o telefone, a tevê e, hoje, a internet e as mídias digitais (LEMOS, 2011, p. 24). 
Desse modo, entende-se que o recurso tecnológico denominado internet é um instrumento que tem sido utilizado e aprimorado pelos movimentos sociais e que tem promovido mudanças nos repertórios adotados através de novos meios de publicização de informações, novas formas de comunicação e coordenação de mobilizações, através da combinação com outras ferramentas que continuam a ser utilizadas, tais como o telefone, a mídia impressa, assim como manifestações presenciais (PEREIRA, 2011, p. 12).

\section{RECURSOS HUMANOS}

A formação dos professores em tecnologia é realmente um dos maiores desafios quando se fala de tecnologia na educação. Não basta apenas instalar uma lousa interativa, por exemplo, e pedir que se saia usando. Dessa forma, ela não será utilizada em sua plenitude e apenas o que é conhecido por eles será colocado em prática. É preciso mostrar a diversidade de atividades que podem ser desenvolvidas por meio de um dispositivo móvel para que isso facilite e, até melhore, os processos de comunicação e de aprendizagem dos alunos. Sobre isso, Leite (2008) afirma que:

[...] a contemporaneidade pressupõe uma sociedade em transformação constante, portanto, exige uma escola em transformação constante e que, por sua vez, exige também professores em transformação constante. [...] O professor passa a ser um estimulador, coordenador e parceiro do processo de ensino e aprendizagem e não mais um mero transmissor de um conhecimento fragmentando em disciplinas (LEITE, 2008, p. 72).

O grande fator desta questão é que os professores utilizam tecnologia para consumir, pesquisar as informações de suas aulas, produzem seu material em arquivo de texto e encerram aqui o percurso tecnológico que poderia ter continuidade. Deve-se pensar, a partir deste ponto, o que o aluno faz com 0 assunto que aprendeu; refletir sobre quais formas gratuitas ele poderia ser coautor neste processo; analisar acerca da falta ao professor para que se aproprie de vez da tecnologia para reconhecê-la como aliada. 
É necessário que os professores se sintam confortáveis para utilizar esses novos auxiliares didáticos. Estar confortável significa conhecêlos, dominar os principais procedimentos técnicos para sua utilização, avaliá-los criticamente e criar novas possibilidades pedagógicas, partindo da integração desses meios com o processo de ensino (KENSKI, 2001, p. 77).

A tecnologia tem influenciado e mudado a forma de realizar e fazer acontecer a comunicação em todos os setores da sociedade. Nada mais comum esperar que o contexto escolar também se aproprie deste recurso para que a aprendizagem faça parte do contexto social em que está inserido. Sobre isso, Villardi e Oliveira (2005) defendem que:

As novas tecnologias de informação e de comunicação fizeram ingressar nos ambientes tecnológicos de treinamento e ensino um poderoso instrumental interacional, capaz de alterar, substantivamente, as possibilidades de relação entre os sujeitos envolvidos e, assim, viabilizar que, nesses ambientes, se criem as condições indispensáveis ao caráter dialógico da educação. (VILLARDI; OLIVEIRA, 2005, p. 36)

O que se evidencia, inclusive, é que há muitas iniciativas que se prestam a organizar teoricamente a prática, mas se afastam da realidade da escola. São professores, pesquisadores e especialistas no assunto que dedicam seus esforços em sugerir soluções, mas sem observar as realidades locais. Freire (1995) traz algumas reflexões sobre esse apontamento.

[...] na formação permanente de professores, o momento fundamental é o da reflexão crítica sobre a prática. É pensando criticamente a prática de hoje ou de ontem que se pode melhorar a próxima prática. O próprio discurso teórico, necessário a reflexão crítica, tem de ser tal modo concreto que quase se confunda com a prática. $O$ seu "distanciamento epistemológico" da prática enquanto objeto de sua análise deve dela "aproximá-lo" ao máximo (FREIRE, 1995, p. 40).

Portanto, os recursos humanos são essenciais até para as iniciativas que inicialmente possam ser consideradas essencialmente digitais. No que tange ao espaço escolar, por mais que iniciativas modernas tentem tornar esse ambiente virtual, necessita que profissionais de educação e apoio técnico-pedagógico que sejam a ponte necessária entre o aluno e o conhecimento. 


\section{MOBILIDADE DIGITAL OU TECNOLOGIAS MÓVEIS}

Não se pode escrever sobre TDICs na educação atual sem mencionar a importância e validade da mobilidade digital, aqui entendida como os smartphones e os tablets que, em sua maioria, têm acesso gratuito por meio do Play Store ${ }^{4}$ aos aplicativos de produção de texto, áudio, imagens, vídeos, além das redes sociais para publicação e promoção destas produções.

Geralmente, disponíveis em plataformas totalmente gratuitas, alunos e professores têm em suas mãos, em um único aparelho, o que há uma década precisaria de um verdadeiro parque tecnológico dentro da escola para que pudesse ter acesso a todos estes recursos.

A mobilidade digital integra-se à sociedade, igualando o acesso à informação e, também, à produção deste mesmo material. Leva a discussão sobre a veracidade das informações publicadas e a mesma rede que produz as fakenews, desvenda se é verídico ou falso. De qualquer forma, se produz conhecimento sobre como adquirir e se apropriar das informações para fazer a diferença no contexto educacional.

Para entender a complexa relação entre aprendizagem e desenvolvimento, Vygotsky (1994) considera dois aspectos: a relação geral entre ambos e os fatores específicos dessa relação, quando a criança chega à fase escolar. Consideração importante é que a aprendizagem se inicia bem antes da vida escolar; assim, muitos conteúdos vistos na escola já foram antes vivenciados. Entende-se que há interação entre aprendizagem com desenvolvimento desde os primeiros dias de vida do ser humano.

A construção coletiva do conhecimento durante 0 processo de aprendizagem, trabalhando ética e respeito norteado teoricamente, como, por exemplo, em Vygotsky e sua teoria de Zona de Desenvolvimento Proximal (ZDP), como sintetizou Almeida (2000):

\footnotetext{
${ }^{4}$ O Play Store é a loja oficial de aplicativos da Google para smartphones e tablets com sistema operacional Android. Nesta loja pode pesquisar, fazer download e instalar aplicativos gratuitos e pagos.
} 
A atitude do professor em propor diálogos cria condições para que a aprendizagem ocorra como um processo dinâmico, que envolve múltiplos elementos: a reflexão defendida por Dewey; a Construção do conhecimento explicitada por Piaget; um ambiente em que o aluno é sujeito da aprendizagem, conforme Freire, e em que o professor atua como mediador, segundo o conceito de Zona Proximal de Desenvolvimento (ZPD) definido por Vigotsky (ALMEIDA, 2000, p. 78).

A ZDP se caracteriza por ser onde ocorre o processo de ensino aprendizagem, sempre entendendo que existe uma Zona de Desenvolvimento Real que se compreende como o que o aluno já sabe fazer sozinho. A Zona de Desenvolvimento Potencial compreende o que o aluno tem possibilidade de aprender. É o ciclo descrição-execução-reflexão-depuração que dirige o aprofundamento de estudos enfocados numa perspectiva interdisciplinar, interrelacionando aspectos de diferentes áreas do conhecimento: teorias da aprendizagem e do desenvolvimento, domínio do computador, ciência da computação, metodologia educacional e outros saberes, objetos de estudo em desenvolvimento (ALMEIDA, 2000).

As atividades desenvolvidas em sala de aula, quando consideram as TDICs, envolvem o suporte da tecnologia e são planejadas de forma a serem desafiadoras, envolvem os conhecimentos e os assuntos estudados pelos alunos. Essa situação envolve o desenvolvimento de espaços semióticos de aprendizagem, com o uso das tecnologias digitais como recurso. Sendo as situações determinadas pelo contexto adequado, a tecnologia pode propiciar um ambiente desafiador e fomentador de ZDP, sendo, através desse contexto, que se dá a formação de um conjunto de elementos interrelacionados de recursos, pessoas e os objetos, que emergem as ZDP.

\section{ESPAÇOS DIGITAIS - SALAS DE INFORMÁTICA}

Em todo o mundo, escolas removeram os computadores das salas de informática, substituindo-os por dispositivos portáteis menores que são usados na sala de aula ou mesmo fora dela. Na maioria dos casos, esses equipamentos - geralmente, tablets - ainda são de propriedade da escola, mas algumas já estão permitindo que os alunos levem seus próprios dispositivos. A vantagem é 
justamente não ficar limitado a um espaço fixo, permitindo que a aprendizagem aconteça em diferentes ambientes - no pátio ou na biblioteca, por exemplo.

O uso do celular em sala de aula é uma questão complexa. No que diz respeito ao controle da classe e do conteúdo acessado pode ser complicado, mas também pode ser uma maneira de o professor envolver os alunos entediados. Um bom primeiro passo é trabalhar com os alunos um conjunto de combinados para o uso dos smartphones em sala, com orientações claras sobre o que é permitido, o que não é e quais são as consequências se houver descumprimento.

A utilização das tecnologias em sala de aula e não em um espaço diferente fomenta a metacognição e o aprendizado autodirigido, já que esse modelo, como afirmam Barbosa e Mora (2013):

[...] fundamenta-se no uso contextualizado de uma situação problema para 0 aprendizado autodirigido. Enquanto que nos métodos convencionais o objetivo é a transmissão do conhecimento centrada no professor, em conteúdos disciplinares, na ABProb, o aprendizado passa a ser centrado no aluno, que deixa de ser um receptor passivo da informação para ser agente ativo por seu aprendizado. Nesse contexto, o professor atua como orientador ou facilitador nos grupos de trabalho ou estudo, nos quais a interação entre professor-aluno é muito mais intensa do que em aulas puramente expositivas (BARBOSA; MOURA, 2013, p. 58).

Como citado por Barbosa e Moura (2013), a ABProb procura transformar um problema como base de motivação para o aprendizado autodirigido, dando ênfase à construção do conhecimento em ambiente de colaboração mútua. A ideia não é ter sempre o problema resolvido na etapa final do trabalho, mas sim enfatizar o processo seguido pelo grupo na busca de uma solução, valorizando a aprendizagem autônoma e cooperativa (BARBOSA; MOURA, 2013, p. 58).

Essas iniciativas integradoras (tecnologias e sala de aula) buscam fomentar iniciativas que busquem a melhoria da qualidade do ensino e a formação de cidadãos que saibam atuar na sociedade de forma crítica seja no cotidiano, seja nos canais digitais. Os alunos devem acessar a informação de modo simplificado para que o conhecimento e sua eventual busca seja um processo natural e não dificultoso, equilibrando oportunidades e igualando os desafios. Sobre isso, Belloni (2009) afirma que 
[...] não pode haver cidadania sem apropriação crítica e criativa, por todos os cidadãos, das mídias que o progresso técnico coloca à disposição da sociedade; e a prática de integrar estas mídias nos processos educacionais em todos os níveis e modalidades, sem o que a educação que oferecemos às novas gerações continuará sendo incompleta e anacrônica, em total dissonância com as demandas sociais e culturais (BELLONI, 2009, p. 1082).

Paralelo às questões levantadas, têm-se o fato de que o que é físico e o que é virtual passou-se a guardar informações em nuvem. A possibilidade de armazenamento e de processamento de dados em um servidor na web, através dos serviços oferecidos pela Computação em Nuvem, permite que uma grande diversidade de dispositivos (tablets, celulares, notebooks e desktops) possa acessar e executar esses recursos, sendo necessário somente o acesso à internet e um mecanismo padronizado, que, por sua vez, pode ser um navegador que necessita poucos recursos computacionais (VANDRESEN; MAGALHÃES, 2013, p. 1).

Ainda, uma mídia é dita digital quando é baseada em tecnologia digital, ou seja, só se diferencia das demais por questões técnicas referentes à sua implementação. O fato de ser digital, isto é, trabalhar diretamente com dígitos ao invés de outras grandezas, traz benefícios técnicos como manutenção da integridade das informações armazenadas ou transmitidas, manipulação simples e rápida dos dados e possibilidade de ser compatível, sendo facilmente adaptável a novos formatos também digitais (MEIRELLES, 2010, p. 16).

Desse modo, a tecnologia móvel pode se tornar uma aliada para as comunidades isoladas. Com a orientação de um professor, por exemplo, os alunos podem acessar conteúdos específicos, aulas online, realizar vídeo chats e outras interações. É claro que a falta de infraestrutura de internet representa um desafio. Há vários exemplos de uso de celular em sala de aula em substituição das salas de informática como o uso de grupos colaborativos usando ferramentas como o WhatsApp para estender a comunicação fora da 
sala de aula. Outras opções de aplicativos são o Slack ${ }^{5}$ e o Telegram ${ }^{6}$, leitura de e-books de forma colaborativa, produção de áudios, fotos e vídeos sobre o tema estudado, e a criação de apresentações e registros colaborativos com programas como o Padlet $^{7}$ e o Evernote 8 .

\section{CONSIDERAÇÕES FINAIS}

A tecnologia propicia ao professor atuar de forma diferente em sala de aula, é possível instigar os alunos a desenvolver pesquisas, investigações, críticas, reflexões, aprimorar e transformar ideias e experiências, não é preciso que professores se tornem donos da verdade e do conhecimento, mas sim parceiros de seus alunos, andando juntos em busca de um mesmo propósito o conhecimento e a aprendizagem. Essa atuação leva os profissionais da educação a se desprender do livro didático, que deixa de ser o guia da prática do professor e passa a ser mais uma, entre outras, fontes de informação e de desenvolvimento do trabalho.

Desta forma, aprofundou-se a discussão e a problematização do assunto, buscando compreender o porquê de muitos professores utilizarem as TDICs para sua própria formação e, em contrapartida, optam pela não utilização em sala de aula. Criou-se, a partir das informações aqui elencadas, condições para o docente construir conhecimento sobre as técnicas computacionais, entender por que e como integrar na sua prática pedagógica e ser capaz de superar barreiras de ordem administrativa e pedagógica deve ser a prioridade (VALENTE, 1999, p. 2).

\footnotetext{
${ }^{5}$ Plataforma de comunicação interna para sua empresa, abrangente e com funcionalidades que lembram um chat que também faz chamadas em vídeo, só que com muito mais capacidade de customização e interação entre os participantes, além de comandos ágeis e facilidade para compartilhar os mais diversos tipos de arquivos.

${ }^{6}$ O Telegram é um serviço de mensagens instantâneas baseado na nuvem. O Telegram está disponível para smartphones ou tablets, computadores e, também, como Aplicação web. Os usuários podem enviar mensagens e trocar fotos, vídeos, stickers e arquivos de qualquer tipo.

7 Padlet é um aplicativo de Internet que permite que as pessoas expressem seus pensamentos sobre um tema comum facilmente. Ele funciona como uma folha de papel on-line onde as pessoas podem colocar qualquer conteúdo (por exemplo, imagens, vídeos, documentos de texto) em qualquer lugar da página, junto com qualquer um, de qualquer dispositivo.

${ }^{8}$ Evernote é um software destinado a organização da informação pessoal mediante um arquivo de notas.
} 


\section{REFERÊNCIAS BIBLIOGRÁFICAS}

ALMEIDA, M. E. B. de. Informática e Formação de Professores. Brasília: SEED, 2000.

BELLONI, M. L. O que é Mídia-Educação. 2. ed., Campinas: Autores Associados, 2009.

BARBOSA, D. N. F. et al. Experiências com o uso de Tablets no Contexto da Educação Escolar E Não Escolar. Revista Prâksis, Novo Hamburgo, v. 2, p. 6780, dec. 2015. ISSN 2448-1939.

BRASIL. Constituição. Constituição da República Federativa do Brasil. Brasília: Senado Federal, 1988.

. Congresso Nacional. Lei n. 9.394, de 20 de dezembro 1996. Lei de Diretrizes e Bases da Educação Nacional. Brasília: DF, 1996.

Diretrizes Curriculares Nacionais Gerais da Educação Básica. Ministério da Educação. Secretaria de Educação Básica. Diretoria de Currículos e Educação Integral. Brasília: MEC, SEB, DICEI, 2013.

FREIRE, P. Pedagogia da autonomia: saberes necessários à prática educativa. Rio de Janeiro: Paz e Terra, 1995.

KENSKI, V. M. Em direção a uma ação docente mediada pelas tecnologias digitais. In BARRETTO, Raquel (org.). Tecnologias Educacionais e Educação à Distância: avaliando políticas e práticas. Rio de Janeiro: Quartet 2001. p. 7484

LEITE, L. S. Mídia e a perspectiva da tecnologia educacional no processo pedagógico contemporâneo. In: Tecnologia e Educação: as mídias na prática docente. Wendel Freire (org.). Rio de Janeiro: Wak Editora, 2008.

LEMOS, A. Cibercultura, tecnologia e vida social na cultura contemporânea. Porto Alegre: Sulina, 2011.

LEMOS, A., COSTA, L. Um modelo de inclusão digital: o caso da cidade de Salvador. In: Eptic Online . Vol. VII, n. VI, Sep. a Dic. 2005. 
MORAN, J. E.; MASETTO, M. T.; BEHRENS, M. A. Novas Tecnologias e Mediação Pedagógica. 15. ed., Campinas: Papirus, 2009.

PEREIRA, D. As Tecnologias de Informação e Comunicação (TICs) como aliadas para 0 desenvolvimento. Disponível em: $<$ http://periodicos.uesb.br/index.php/cadernosdeciencias/article/viewFile/884/89 1>. Acesso em 09 mar. 2021.

PRETTO, N. D. L. Professores autores em rede. In: SANTANA, B.; ROSSINI, C.; PRETTO, N. D. L. Recursos Educacionais Abertos - Práticas colaborativas e políticas públicas. São Paulo: Casa da Cultura Digital, 2012.

SEVERINO, A. J. Metodologia do trabalho científico. 23. ed. rev. e atual. São Paulo: Cortez, 2007.

TAJRA, S. F. Informática na Educação: novas ferramentas pedagógicas para o professor da atualidade. - 8. ed. rev. e ampl. - São Paulo: Érica, 2008.

VANDRESEN, R. S.; MAGALHÃES, W. B. Conceitos e Aplicações da Computação em Nuvem. Universidade Paranaense. Paranavaí, 2013.

VALENTE, José. Armando. As tecnologias digitais e os diferentes letramentos. In: Pátio Revista Pedagógica. N. 44. (nov. 2007/jan. 2008). p. 12-15.

VILLARDI, R.; OLIVEIRA, E. G. Tecnologia na Educação. Uma perspectiva sociointeracionista. Rio de Janeiro: Dunya, 2005.

VYGOTSKI, L. S. Obras escogidas (Vol. 1). Madrid, Espanha: Visor, 1991. 